\title{
Entrevista
}

\section{Lexicografía Pedagógica/Didáctica: entrevista con María Teresa Fuentes Morán ${ }^{1}$}

Claudia Zavaglia*

Odair Luiz Nadin **

En la bibliografía española se suele usar la terminología Lexicografía Didáctica; en Brasil se ha optado, en la mayoría de los casos, por Lexicografía Pedagógica. ¿Pedagógica o Didáctica? Desde su punto de vista, ¿qué terminología refleja mejor los objetos y objetivos de esta área de la Lexicografía?

La tradición lexicográfica en español optó por la denominación didáctica. Actualmente hay cierta controversia al respecto y en algunos círculos se prefiere pedagógica. Esto viene motivado bien por un calco de otras lenguas o bien por un apropiado intento de ajustar la denominación a los avances en el ámbito de las Ciencias Sociales. En mi opinión, si estamos hablando del diseño, uso y valoración de diccionarios entendidos como una de las herramientas para la enseñanza y aprendizaje del componente léxico de la lengua, hablamos de lo mismo. Ninguno de los dos términos aporta más precisión que el otro.

\footnotetext{
${ }^{1}$ María Teresa Fuentes Morán es doctora en Lingüística por la Universidad de Augsburgo, Alemania (1996). Es lexicógrafa, traductora y profesora de lengua española en la Faculdad de Traducción y Documentación de la Universidad de Salamanca, España.

${ }^{*}$ UNESP/S. J. Rio Preto.

${ }^{* *}$ UNESP/Araraquara.
} 
1. ¿Cuáles es, a partir de su experiencia en la elaboración de diferentes tipos de diccionarios, el punto inicial de un proyecto de elaboración de diccionarios pedagógicos/didácticos? Dicho de otro modo, ¿por dónde empezamos?

Muchos de los que hemos escrito diccionarios hemos escuchado la pregunta - ¿otro? ¿no hay ya muchos? Esta ingenua cuestión esconde el punto de arranque de cualquier proyecto lexicográfico: ¿qué queremos aportar? La respuesta, claro está, puede ser de índole muy diversa -actualidad, precisión, nuevos tipos de información, nuevos formatos, ...-, y debe estar presente a lo largo del todo el desarrollo del trabajo, en cada una de las muchas decisiones que se toman en el proceso. Esto es lo que nos hace no perder el horizonte y lo que impregna el diseño del programa informativo del diccionario, primer paso esencial en el trabajo lexicográfico.

2. ¿Hay objetos que podríamos considerar canónicos de la Lexicografía Pedagógica o Didáctica? Es decir, ¿qué obras son su objeto de estudio propio?

La lexicografía didáctica tiene un ámbito de actuación que se ve modificado y ampliado de acuerdo con la evolución de las necesidades de sus destinatarios; así debe ser, como en otras muchas esferas de conocimiento. En el campo del español, hablábamos de diccionarios infantiles y de escolares; en su momento se sumó, por fin, el español general como lengua extranjera. Sin embargo, en mi opinión, la metalexicografía didáctica ha tardado demasiado en aceptar o en entender gran parte de la lexicografía bilingüe como campo necesario de actuación. No le cerraremos las puertas al mar, por ejemplo, al español para fines específicos y ¿quién sabe a qué más? Ampliar objetos de estudio y objetivos no es perder la esencia ni salirse del propio campo. 
3. Respecto a la forma y la función de los ejemplos, ¿qué opina sobre el límite entre la autenticidad y la adaptación de ejemplos para diccionarios pedagógicos/didácticos?

Hay un aspecto lingüístico-textual en cuanto a los ejemplos que un lexicógrafo no debe perder de vista: un ejemplo extraído de un texto e incrustado en artículo lexicográfico pierde el contexto que lo caracteriza y, por lo tanto, simplificando la expresión, deja de ser un ejemplo real. Puede tener naturaleza documental, pero no es auténtico. El valor documental en un diccionario didáctico no es esencial; por ello, habría que perder el miedo a adaptar los ejemplos y con ello acrecentar su valor informativo y didáctico.

4. En la Lexicografía Bilingüe se han desarrollado muchas investigaciones y discusiones sobre la dicotomía diccionario activo/diccionario pasivo. Hoy día, con los diccionarios electrónicos, ¿esa dicotomía todavía cumple alguna función?

La dicotomía activo/pasivo supuso un avance significativo en términos teóricos y la lexicografía práctica se ha beneficiado de ello, no hay duda. Cierto es que se ha estudiado desde perspectivas diversas, no siempre convergentes; pero, en mi opinión, sería un error abandonar este tipo de reflexión precisamente ahora, en un momento en el presenciamos modificaciones esenciales en las formas de uso de los diccionarios y en el que algunas de las formas de codificar o decodificar textos también se están viendo transformadas.

5. En el actual mundo globalizado y de intercambios múltiples y rápidos de información, en que las lenguas se entrecruzan de una forma que hasta ahora nos habría parecido imposible, ¿existe una manera de resolver el problema de las variedades (léxicas, fonéticas, etc.) en diccionarios pedagógicos/didácticos? 
El problema afecta a todas las esferas de las disciplinas relacionadas con la lengua y a muchas otras. Asistimos a cambios que probablemente harán evolucionar la esencia misma del concepto de variedad. En cuanto al español, es un reto para la lexicografía actual desarrollar formas de presentación de los datos léxicos que sirvan para reflejar el pluricentrismo de nuestra lengua, sin jerarquías implícitas. No obstante, la lexicografía puede intentar responder a la cuestión de cómo, pero la cuestión de qué datos fiables recoger debe plantearla junto con los estudios más avanzados sobre variación, sociolingüística, didácticas de lengua, etc. No sé cuál es la respuesta a ese reto, pero sí que es una necesidad acuciante afrontarlo si queremos diccionarios útiles y fidedigno.

6. En la era de la tecnología y de Internet, ¿todavía merece la pena elaborar diccionarios?

Hoy más que nunca. Las abrumadoras posibilidades actuales de acceso a textos han ampliado exponencialmente las necesidades de herramientas para su correcta decodificación. A su vez, los nuevos flujos de comunicación hacen más necesarias herramientas para la codificación. La avalancha de datos léxicos, en muy diversos formatos, a los que podemos acceder en los últimos años a través de Internet no hace más que poner de manifiesto una necesidad. No caigamos nosotros mismos en la misma ingenua pregunta de ¿otro? ¿no hay ya muchos? Hoy más que nunca hacen falta diccionarios fiables y accesibles que, como decíamos al principio, aporten novedades y se adapten a las cambiantes necesidades de información léxica que observamos en estas nuevas generaciones y en las venideras. 